\title{
ANÁLISE DOS IMPACTOS DA CONCESSÃO DO SETOR FERROVIÁRIO DE CARGAS NA DÉCADA DE 1990
}

\section{ANALYSIS OF THE IMPACTS OF THE RAILWAY LOAD SECTOR CONCESSION IN THE $1990 \mathrm{~S}$}

\author{
Víctor Borges da Silva ${ }^{1 *}$, Edson T. Vieira², Marilsa de Sá Rodrigues ${ }^{3}$, Edson A. A. Querido Oliveira ${ }^{4}$ \\ ${ }^{1}$ Mestrando em Gestão e Desenvolvimento Regional na Universidade de Taubaté (UNITAU), Taubaté, SP, Brasil, \\ victor_bs@yahoo.com.br* \\ ${ }^{2}$ Doutor em História Econômica, Professor do programa de pós-graduação em Gestão e Desenvolvimento Regional da Universidade \\ de Taubaté (UNITAU), Taubaté, SP, Brasil, etrajanov@gmail.com \\ ${ }^{3}$ Doutora em Administração de Empresas, Professora do programa de pós-graduação em Gestão e Desenvolvimento Regional da \\ Universidade de Taubaté (UNITAU), Taubaté, SP, Brasil, marilsasarodrigues@hotmail.com \\ ${ }^{4}$ Doutor em Engenharia Aeronáutica e Mecânica, Professor do programa de pós-graduação em Gestão e Desenvolvimento Regional \\ da Universidade de Taubaté (UNITAU), Taubaté, SP, Brasil, edsonaaqo@gmail.com
}

\section{Resumo}

Se uma nação quer ser desenvolvida, com certeza deve ter uma matriz de transportes consolidada. Quando um país possui grandes extensões territoriais, o transporte ferroviário de cargas deve ter a maior participação na matriz de transportes, por ser um modal capaz de transportar grandes volumes de cargas em médias e longas distâncias. 0 processo de concessão das malhas ferroviárias foi uma forma de eliminar as dívidas do setor ferroviário brasileiro e fazer com que o modal ganhasse mais investimentos e tivesse maior participação na matriz de transportes. Dessa forma, este estudo objetiva realizar uma análise dos impactos que as concessões na década de 1990 trouxeram para o setor ferroviário. Para alcançar os resultados, foi realizada uma análise documental e bibliográfica. À vista disto, verificou-se um aumento de investimentos tanto do setor privado quanto do setor público, redução no número de acidentes, aumento de empregos diretos e indiretos e maior participação na produção de transporte de cargas. Também foi possível verificar que o minério de ferro é a carga que tem o maior volume de transporte pelo modal ferroviário, chegando a quase $80 \%$ de toda carga que foi transportada no ano de 2018 . Destarte, a conclusão, a partir das pesquisas e análises, é que após a concessão houve mais impactos positivos do que negativos. Adicionalmente, sugere-se como tema para futuras pesquisas, os impactos que as concessões trouxeram para o transporte ferroviário de passageiros.

Palavras-chave: Transporte ferroviário de cargas. Concessão. Investimentos.

\begin{abstract}
In order to be developed, a nation must have a consolidated transport matrix. When a nation has large territorial extensions, rail freight transport must have the largest share in the transport matrix as it is a modal capable of transporting large volumes of freight over medium and long distances. The process of granting railway networks was a way of eliminating the Brazilian railway sector debts and making the modal gain more investments and have a greater participation in the transport matrix. Thus, this study aims to carry out an analysis of the impacts that the concessions in the 1990s brought to the railway sector. To achieve the results, a documentary and bibliographic analysis was carried out. Hence, there was an increase in investments in both private and public sectors, a decrease in the number of accidents, an increase in direct and indirect jobs and greater participation in the production of cargo transportation. It was also possible to verify that iron ore is the largest volume transported on rail tracks, reaching almost $80 \%$ of all freight that was transported in 2018. Thus, based on research and analysis, the conclusion is that after the concession there were more positive than negative impacts. Additionally, the impacts that the concessions brought to the rail passenger transport this suggested as a theme for future researches.
\end{abstract}

Keywords: Rail freight transport. Concession. Investments. 


\section{INTRODUÇÃO}

O transporte ferroviário é um modal altamente estratégico, principalmente quando o assunto envolve países com grandes dimensões continentais. Lohmann e Oliveira (2008) acrescentam que o transporte de cargas é altamente competitivo nos países com grandes extensões territoriais e, para muitos, é considerado como meio de transporte pioneiro na modalidade de passageiros, no que diz respeito a viagens turísticas.

De acordo com Júnior et al. (2018), apesar de o Brasil ser um país com dimensões favoráveis à implantação do modal ferroviário, ele possui uma malha relativamente pequena se comparada à sua extensão territorial, e ainda assim privilegia o transporte rodoviário.

A pequena e deficiente extensão das ferrovias é visível quando comparamos o Brasil com outros países. Para fins de comparação, os Estados Unidos da América possuem quase 14 vezes mais estradas de ferros do que o Brasil. O foco nos sistemas rodoviários torna o transporte produtivo mais caro, e isso fica ainda pior quando o cenário é de um país com grandes extensões territoriais e com grande volume de cargas (CORDEIRO, 2016, apud JUNIOR et al., 2018).

O modal ferroviário tem mais de 20 anos desde os primeiros sinais da concessão das malhas ferroviárias brasileiras. Antes das concessões, as ferrovias vivenciavam um cenário deteriorado, de abandono e de péssima infraestrutura dos trilhos, pontes, viadutos e do material rodante como vagões e locomotivas (RESENDE et al., 2009).

Diante do cenário desesperador, o Governo Federal decidiu conceder a Rede Ferroviária Federal (RFFSA) à iniciativa privada, de forma que as empresas pudessem explorar os trechos ferroviários no país, seja no ramo de produção e exportação ou apenas no ramo de transporte de passageiros. Dessa forma, a malha ferroviária brasileira passou a receber importantes investimentos, com o objetivo de recuperar o que estava deteriorado e também de aumentar o volume de cargas, trazendo de volta a luta por um maior equilíbrio na matriz de transportes do Brasil (RESENDE et al., 2009).

Segundo Lohmann e Oliveira (2008), comparado ao Brasil, o processo de concessão na área de infraestrutura começou dez anos antes em diversos países. Knowles (1998) demonstra a Inglaterra como exemplo e diz que nas décadas de 1980 e 1990 adotava políticas de governo de cunho neoliberais que resultaram em privatizações de diversos setores da economia.

Nesse contexto, observa-se que desde o ano 2016, com a ascensão do governo Temer, o Brasil passou a adotar uma postura mais neoliberal e conservadora, em relação à ideologia política dos governos anteriores (POCHMANN, 2017).

Parecido com as políticas neoliberais da Inglaterra citadas acima, o atual governo brasileiro voltou a pensar em pacotes de concessões de âmbito nacional. Para constatar essa nova postura neoliberal, atualmente pode-se observar a privatização e concessão de diversas empresas estatais, com destaque para a concessão em 31 julho de 2019 da Ferrovia Norte-Sul, trecho com 1.537 km de extensão, concedido à Rumo Malha Central S.A. (ANTT, 2019).

Diante do exposto, o presente artigo busca realizar uma análise dos impactos que as concessões na década de 1990 trouxeram para o setor ferroviário. Para alcançar o objetivo proposto, este estudo está estruturado em cinco seções, sendo que a primeira compreende esta introdução. A segunda seção, apresenta-se por uma breve revisão de literatura, destacando as principais características do modal ferroviário e da concessão da malha ferroviária que ocorreram na década de 1990, a fim de que o leitor compreenda melhor as próximas etapas deste estudo. A 
seção três, compreende os aspectos metodológicos empregados neste artigo. Na quarta, é realizada uma breve discussão dos avanços em termos de investimentos no modal ferroviário e os avanços na produção de transporte de cargas. Por fim, a seção cinco destina-se a apresentar as conclusões deste estudo.

\section{REVISÃO DA LITERATURA}

\subsection{Modal ferroviário}

O modal ferroviário compreende uma modalidade de transporte voltada para a movimentação de cargas e passageiros em médias e longas distâncias. No que diz respeito ao transporte de cargas, suas principais características são o baixo valor agregado e as grandes quantidades (ILOS, 2002).

A matriz de transporte brasileira tem predominância quase absoluta do modal rodoviário e, quando comparamos o Brasil com potências mundiais de extensões territoriais similares, fica claro que o país necessita aumentar a representatividade do setor ferroviário na matriz de transporte, bem como expandir rapidamente a extensão da malha ferroviária.

A figura 1 demonstra os dados comparativos de participação da matriz de transportes de alguns países com o mesmo porte territorial do Brasil.

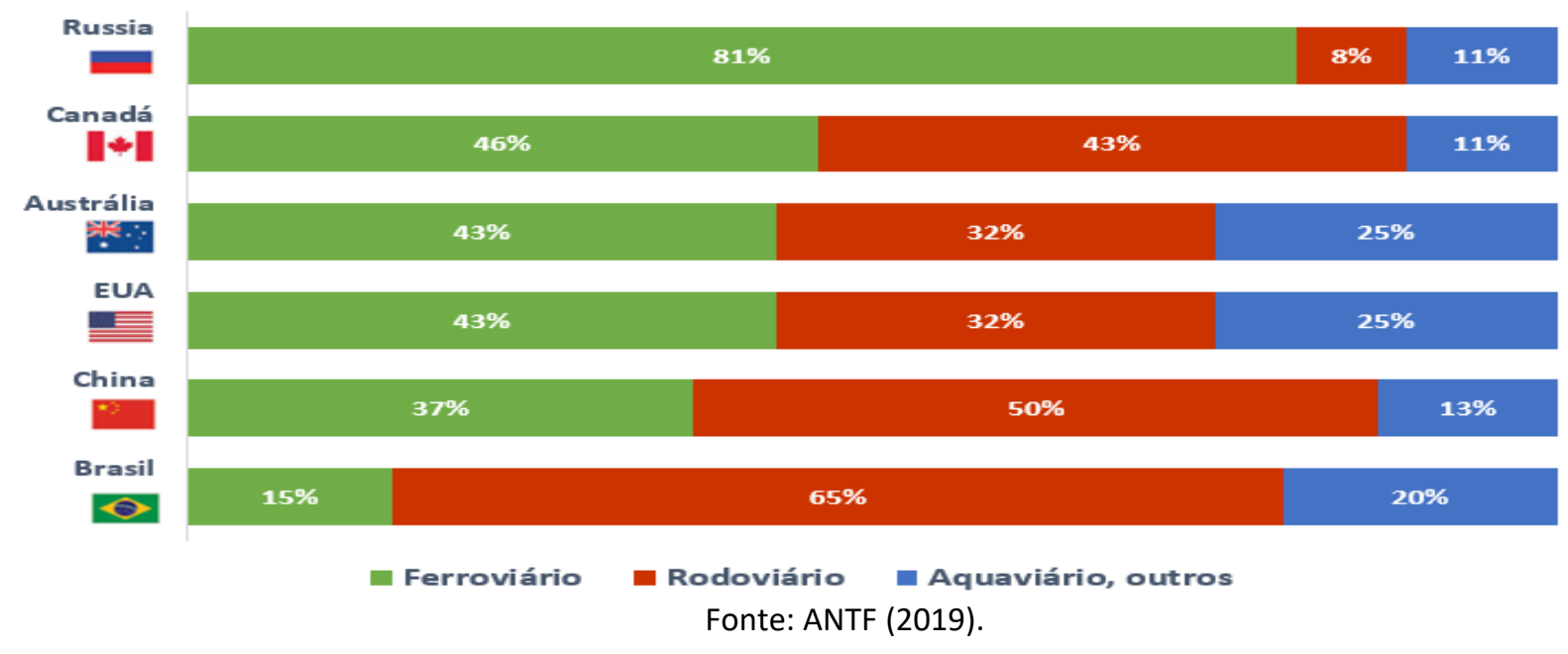

Figura 1 - Comparação de matrizes de transporte de carga

A Rússia é o país que detém a maior representatividade na matriz de transporte, com $80 \%$ de participação do modal ferroviário. Já os Estados Unidos da América, apesar de serem o 4우 país com maior representatividade do modal ferroviário na matriz de transporte de carga, é a nação que detém a maior movimentação mundial de cargas e maior malha ferroviária do mundo, com 295 mil km (ANTF, 2019).

Segundo o Ministério da Infraestrutura (2019), as principais cargas transportadas pelo setor ferroviário brasileiro são: minério de ferro, soja, açúcar, carvão mineral, milho, farelo de soja, óleo diesel, celulose, produtos siderúrgicos e ferro gusa. 
De acordo com a ANTT (2016), algumas das principais terminologias utilizadas para a medição da produção do transporte ferroviário de cargas é descrita abaixo:

- Tonelada Útil (tu) - Total de carga movimentada no transporte remunerado;

- Tonelada-Quilômetro Útil (tku) - Unidade de medida equivalente ao transporte de uma tonelada útil a distância de um quilômetro;

- Tonelada-Quilômetro Bruto - (tkb) - Unidade de aferição do trabalho equivalente ao deslocamento de uma tonelada de trem;

- Acidente Ferroviário - Ocorrência que, com a participação direta de veículo ferroviário, provoca dano a este, a instalação fixa, a pessoa, animal e/ou outro veículo etc; e

- Passageiro x km - É o trabalho equivalente ao transporte de passageiro por um quilômetro.

Cabe ressaltar que a terminologia básica utilizada neste artigo para fins de comparação e análise será Tonelada-Quilômetro útil (tku).

\subsection{Concessão da malha ferroviária brasileira na década de 1990}

Antes das construções das primeiras ferrovias no Brasil, o café era o principal produto destinado à exportação. Anualmente chegavam ao porto de Santos cerca de 200 mil animais carregando sacas de café e outros produtos agrícolas para exportação (DNIT, 2019).

Em 1854, foi inaugurada por D. Pedro II a estrada de ferro Baroneza, primeira ferrovia nacional, criada por iniciativa do Barão de Mauá, Irineu Evangelista de Souza. A ferrovia Baroneza foi objeto do primeiro sistema de concessões de que se tem notícia no país e possuía $14,5 \mathrm{~km}$ de extensão (IPEA, 2010 apud JUNIOR et al., 2018).

Um século depois da criação da primeira estrada de ferro, a malha ferroviária brasileira já tinha sido expandida consideravelmente. Foi em 1957, através da Lei no 3.115, criada pelo governo a RFFSA - a sociedade anônima Rede Ferroviária Federal S.A, onde o governo realizou a unificação administrativa de 18 estradas de ferro à união, que na época tinham 37.000 de malha ferroviária (JUNIOR et al., 2018).

Quase 40 anos depois da criação da RFFSA, após prejuízos operacionais que chegavam a US\$ 1 milhão por dia, forneciam enorme ônus aos cofres públicos e geravam grandes déficits, o governo então decidiu conceder à iniciativa priva a Rede Ferroviária Federal, incluindo-a no PND (Programa Nacional de Desestatização) em 1992 (JÚNIOR et al, 2018; RESENDE et al., 2009).

Ainda sobre as imensas dívidas da RFFSA, de acordo com a ANTF (2012), no período de 1994 a 1997, a União tinha uma dívida de $\mathrm{R} \$ 2,2$ bilhões com as ferrovias e déficits anuais de operação no valor de $\mathrm{R} \$ 300$ milhões.

Antes do sistema de concessão da década de 1990, as ferrovias no Brasil não eram administradas por apenas um órgão estatal. O governo federal era responsável pela administração e operação da RFFSA, que detinha $77 \%$ da malha do país. A Estrada de Ferro Vitória Minas (EFVM) e a Estrada de Ferro dos Carajás (EFC) representavam 68\% do total de produção do setor em 1995 e eram administradas e operadas pela estatal Companhia Vale do Rio Doce. Por último, com apenas 4,5\% da produção de transporte ferroviário em 1995, a Ferrovia Paulista S.A. (FEPASA) era controlada pelo governo do estado de São Paulo (ILOS, 2002).

De acordo com a ANTF (2012), foram concedidas $28.366 \mathrm{~km}$ de malhas ferroviárias para a iniciativa privada no período de 1996 a 1999. Dessa forma, as malhas Transnordestina Logística, 
Estrada de Ferro Vitória Minas, Estrada de Ferro dos Carajás, Ferrovia Centro Atlântica, América Latina Logística Malha Paulista, América Latina Logística Malha Norte, América Latina Logística Malha Oeste, América Latina Logística Malha Sul, Ferrovia Tereza Cristina, MRS Logística e Tramo Norte da Ferrovia Norte Sul foram todas concedidas à iniciativa privada.

Para Lima (1999), a concessão da RFFSA, apesar de ter sido realizada pelo preço mínimo de leilão, foi uma decisão que deve ser entendida, pois serviu a reativação do setor sem gerar maiores pressões sobre as finanças públicas.

De acordo com Junior et al. (2018) o valor de leilão da FEPASA e RFSSA juntas não chegou ao valor de R\$ 2 bilhões de reais e seus prejuízos, nos três últimos anos antes da concessão, ultrapassaram a casa dos $\mathrm{R} \$ \mathrm{~b}$ bilhões.

Um aspecto importante que deve ser observado é que na criação da RFFSA, em 1957, a malha ferroviária tinha quase $37.000 \mathrm{~km}$ de ferroviais e, em 1996 quando foi concedida à inciativa privada, teve uma redução de pouco mais de $7.000 \mathrm{~km}$, chegando a $29.917 \mathrm{~km}$.

Essa redução ainda é citada por Lima (1999), que afirma que em menos de 20 anos as ferrovias brasileiras perderam cerca de $7.000 \mathrm{~km}$ de linhas, trechos que tinham sido criados sem uma análise macroeconômica integrada.

Para Krüger (2003), conforme citado por Resende (2009), a motivação da concessão na década de 1990 estava no alcance da intermodalidade e da melhoria na ligação entre portos e centros produtores, gerando resultados que diminuiriam muito o chamado risco ou custo Brasil.

Nesse contexto, a concessão da Ferrovia Norte-Sul em 2019 atende aos mesmos objetivos das concessões da década de 1990, pois segundo a ANTT $(2019$, p.1) “[...] a ferrovia foi projetada para promover a integração nacional, interligar os principais portos do país, gerar maior competitividade e minimizar os custos de transporte por meio de conexões ferroviárias já existentes, bem como aquelas que ainda serão construídas."

\section{MATERIAIS E MÉTODOS}

Este artigo caracteriza-se metodologicamente como uma pesquisa bibliográfica e documental, uma vez que sua finalidade foi levantar informações sobre a concessão do transporte ferroviário na década de 1990, características do modal ferroviário e investimentos no setor ferroviário com ênfase no transporte de cargas.

Pode-se inferir que a pesquisa bibliográfica "[...] trata-se do levantamento de toda a bibliografia já publicada em forma de livros, revistas, publicações avulsas e imprensa escrita. Sua finalidade é colocar o pesquisador em contato direto com tudo aquilo que foi escrito sobre determinado assunto." (MARCONI; LAKATOS, 2011, p. 43).

À vista disso, os trabalhos selecionados para compor a revisão bibliográfica deste estudo foram extraídos das mais variadas bases de dados disponíveis para os cientistas sociais, como por exemplo: Scientific Electronic Library Online (Scielo); Portal de Periódicos (CAPES/MEC); e Web of Science.

Outrossim, está pesquisa também é caracterizada como do tipo documental. Dessa forma, as autoras Marconi e Lakatos (2011, p. 44) afirmam que a pesquisa documental reúne "[...] todos os materiais, ainda não elaborados, escritos ou não, que podem servir como fonte de informação para a pesquisa científica". 
Ainda com relação ao tipo de pesquisa, é proveitoso pautar-se em Selltiz et al. (1975, p. 358), os quais discorrem que "[...]o emprego de registros estatísticos já existentes exige que o cientista social conheça as melhores fontes de tais dados e apresente certa capacidade inventiva para descobrir material menos conhecido."

Dessa forma, as melhores fontes disponíveis para a extração dos dados relativos aos investimentos (público/privado), projetos em andamento e evolução no transporte ferroviário de cargas foram extraídos de sites governamentais, anuários estatísticos, agências nacionais reguladoras do modal ferroviário e concessionárias de transporte ferroviário. Vale ressaltar que todas as fontes encontram-se na lista de referências deste artigo.

O período de análise foi determinado a partir da data da primeira concessão, ou seja, uma análise entre 1996 e abril de 2019. Os dados foram retirados em sua maioria do portal do Ministério da Infraestrutura, no qual demonstrou todo o período após a concessão.

\section{RESULTADOS E DISCUSSÃO}

\subsection{Investimentos e melhorias após a concessão do setor ferroviário}

Os primeiros investimentos em transporte ferroviário no Brasil começaram no século XIX com influência do capital inglês, interessados nas altas taxas de retorno principalmente para o escoamento da produção cafeeira, tendo a Estrada de Ferro Santos-Jundiaí como sua principal representante (NEWTON 1997, apud RESENDE 2009).

Na década de 1980, o nível de investimentos no setor ferroviário para a conservação, manutenção e ampliação do sistema foi muito pequeno, resultando assim em pouquíssima eficiência operacional e baixa qualidade na prestação de serviços (ILOS, 2002).

Dessa forma, um importante aspecto que deve ser observado depois da concessão do setor ferroviário são os investimentos que vêm sendo feito nas malhas ferroviárias desde a concessão da década de 1990. De acordo com o Ministério da Infraestrutura (2019), a Tabela 1 demonstra os investimentos realizados pela União no setor ferroviário no período de 1995 a abril de 2019.

Tabela 1 - Investimento no setor ferroviário realizado pela União

\begin{tabular}{|c|c|c|c|}
\hline 1995 & 22.276 & 2008 & 918.212 \\
\hline 1996 & 82.561 & 2009 & 998.385 \\
\hline 1997 & 156.017 & 2010 & 2.544 .059 \\
\hline 1998 & 143.795 & 2011 & 1.767.350 \\
\hline 1999 & 65.585 & 2012 & 1.080 .864 \\
\hline 2000 & 59.812 & 2013 & 2.708 .528 \\
\hline 2001 & 70.895 & 2014 & 2.735 .100 \\
\hline 2002 & 72.185 & 2015 & 2.177 .416 \\
\hline 2003 & 37.895 & 2016 & 975.783 \\
\hline 2004 & 107.464 & 2017 & 613.481 \\
\hline 2005 & 230.172 & 2018 & 649.950 \\
\hline 2006 & 333.816 & 2019 (até abr) & 189.816 \\
\hline 2007 & 519.163 & Total & 19.260 .580 \\
\hline
\end{tabular}

Fonte: Elaborado pelos autores a partir de Ministério da Infraestrutura (2019) 
Em um período de 10 anos, de 1995 a 2005, os investimentos realizados pela união não ultrapassaram o valor de R\$ 250 milhões. Após esse período, pode-se observar que os investimentos começaram a subir significativamente, com destaque na diferença de investimentos do ano de 2009 para o ano de 2010, que representa uma taxa de percentual de crescimento na ordem de aproximadamente $155 \%$.

Segundo Resende (2009), quando comparado com a iniciativa privada, a União não investiu quase nada no período pós concessão. Essa informação pode ser constatada na figura 2, que demonstra os investimentos realizados pela iniciativa privada desde as concessões da década de 1990.

É nítida a grande diferença de investimentos entre os setores privado e público. Enquanto o Estado em um período de 20 anos investiu pouco mais de $\mathrm{R} \$ 19$ bilhões, a iniciativa privada no mesmo período investiu nas ferroviais mais de $\mathrm{R} \$ 60$ bilhões.

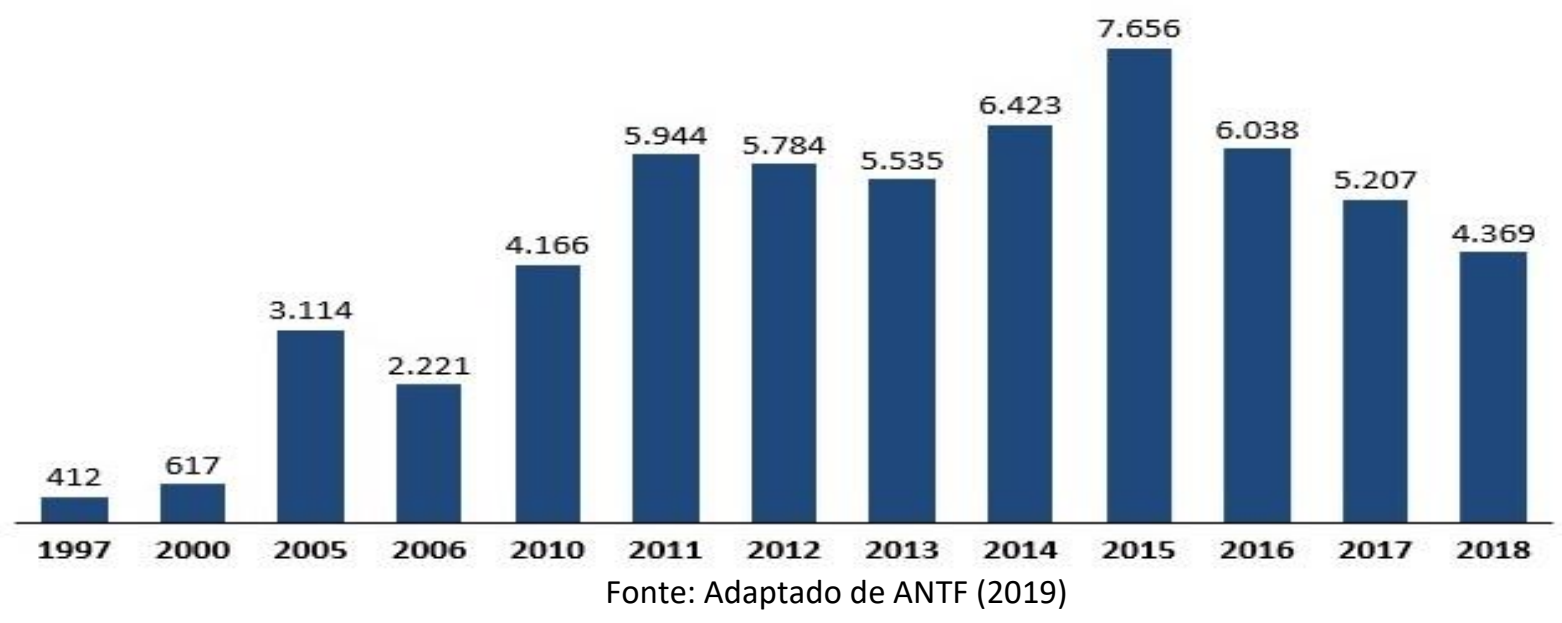

Figura 2 - Investimentos nas ferrovias em milhões pelo setor privado

De acordo com Santos et al. (2016), a concessão da malha ferroviária ajudou de forma significativa no que diz respeito aos investimentos do setor, contribuindo tanto com a retomada da construção de outras linhas como também com a manutenção dos trilhos e vagões, fora a introdução de novas tecnologias de tráfego.

Porém, Resende (2009), em seu estudo, constatou que os atuais usuários das malhas ferroviárias afirmam que a responsabilidade pelos investimentos relacionados à expansão e manutenção da malha deveria ser do governo, por se tratar de um investimento com características estruturantes, seja em uma esfera nacional ou regional.

Ainda, segundo Resende (2009), os altos custos de se obter uma concessão mais os pesados investimentos em manutenção e expansão da malha, acabam impactando nos preços que os usuários pagam e, consequentemente, impactam nos custos dos transportes e no preço dos produtos que chegam ao cliente final.

Outro fator importante que deve ser destacado é a expansão da malha ferroviária, a qual vem recebendo massivos investimentos da iniciativa privada, porém com apenas $30,6 \mathrm{mil} \mathrm{km}$ de ferrovias implantadas. (MINISTÉRIO DA INFRAESTRUTURA, 2019). 
Dessa forma, vê-se que desde a concessão do setor até os dias atuais, pouco se evoluiu no que diz respeito à malha ferroviária, pois pouco mais de 20 anos atrás a malha tinha quase 30 mil $\mathrm{km}$ de extensão, e hoje continua com os mesmos $30 \mathrm{mil} \mathrm{km}$.

De acordo com o Ministério dos Transportes (2019), atualmente existem três projetos ferroviários em andamento, conforme pode ser observado na Tabela 2.

Tabela 2 - Projetos do setor ferroviário

\begin{tabular}{l|l|l|l}
\hline \multicolumn{1}{c|}{ Ferrovia } & \multicolumn{1}{c|}{ Trecho } & Estágio Atual & \multicolumn{1}{c}{ Extensão Final } \\
\hline Ferrovia Norte Sul & Ouro Verde/GO - Estrela D 'Oeste/SP & $682 \mathrm{~km}$ & $4.155,6 \mathrm{~km}$ \\
\hline Ferrovia de Integração Oeste-Leste & Ilhéus/BA - Figueirópolis/TO & - & $1.527 \mathrm{~km}$ \\
\hline Ferrovia Nova Transnordestina & Piauí, Ceará e Pernambuco & $600 \mathrm{~km}$ & $1.753 \mathrm{~km}$ \\
\hline
\end{tabular}

Fonte: Elaborado pelos autores a partir de Ministério da Infraestrutura (2019)

Dentre as obras que estão em construção, destaca-se a Ferrovia Nova Transnordestina que será destinada ao transporte de commodities (granéis sólidos), entre elas o minério de ferro da região sudeste do Piauí e a produção de grãos do cerrado, na região sudoeste do mesmo Estado. Segundo a CNS - Companhia de Siderúrgica Nacional (2018), após concluída, "A Transnordestina busca levar desenvolvimento para o Nordeste brasileiro gerando o menor impacto possível na vida das pessoas e comunidades, além do meio ambiente".

No entanto, a obra da ferrovia transnordestina encontra-se com problemas. Desde 2017, o Tribunal de Contas da União recomenda a interrupção dos gastos com a obra devido à irregularidades. A obra já consumiu R\$ 6 bilhões e, até novembro de 2019, apenas 600 quilômetros tinham sido construídos (BRASIL, 2019).

Além dos projetos de expansão e conservação da malha ferroviária, impactos positivos também foram observados, como a redução de $86 \%$ no índice de acidentes, os números de empregos diretos e indiretos que aumentaram em 128\% desde 1997 (saindo de 16.662 para 38.013, em 2018) e o aumento na participação na matriz de transportes brasileira (ANTF, 2019).

\subsection{Transporte de cargas após a concessão do setor ferroviário}

O transporte de cargas no Brasil nunca teve muita representatividade, pois trata-se de um modal destinado ao transporte de produtos com baixo valor agregado e para longas distâncias. Conforme já citado, a participação do país no transporte de cargas é comparada a países da Europa, que contém dimensões territoriais bem menores que o Brasil (ILOS, 2002).

Segundo a ANTT (2019), no ano de 2018, as principais cargas transportadas pelo modal ferroviário foram, respectivamente: minério de ferro, soja e farelo de soja, produtos da indústria siderúrgica, produção agrícola, açúcar, carvão/coque, combustível (derivados do petróleo e álcool), extração vegetal e celulose, granéis minerais, contêiners, adubos e fertilizantes, cimento, produtos da indústria cimenteira e construção civil e carga geral não conteinerizada.

Mesmo com pouca representatividade na matriz de transporte, o setor ferroviário aumentou drasticamente a movimentação de cargas após a concessão. 0 gráfico 1 demonstra a evolução no transporte de cargas desde a concessão da malha ferroviária. 
Gráfico 1 - Evolução da produção do transporte ferroviário em milhões de TKU

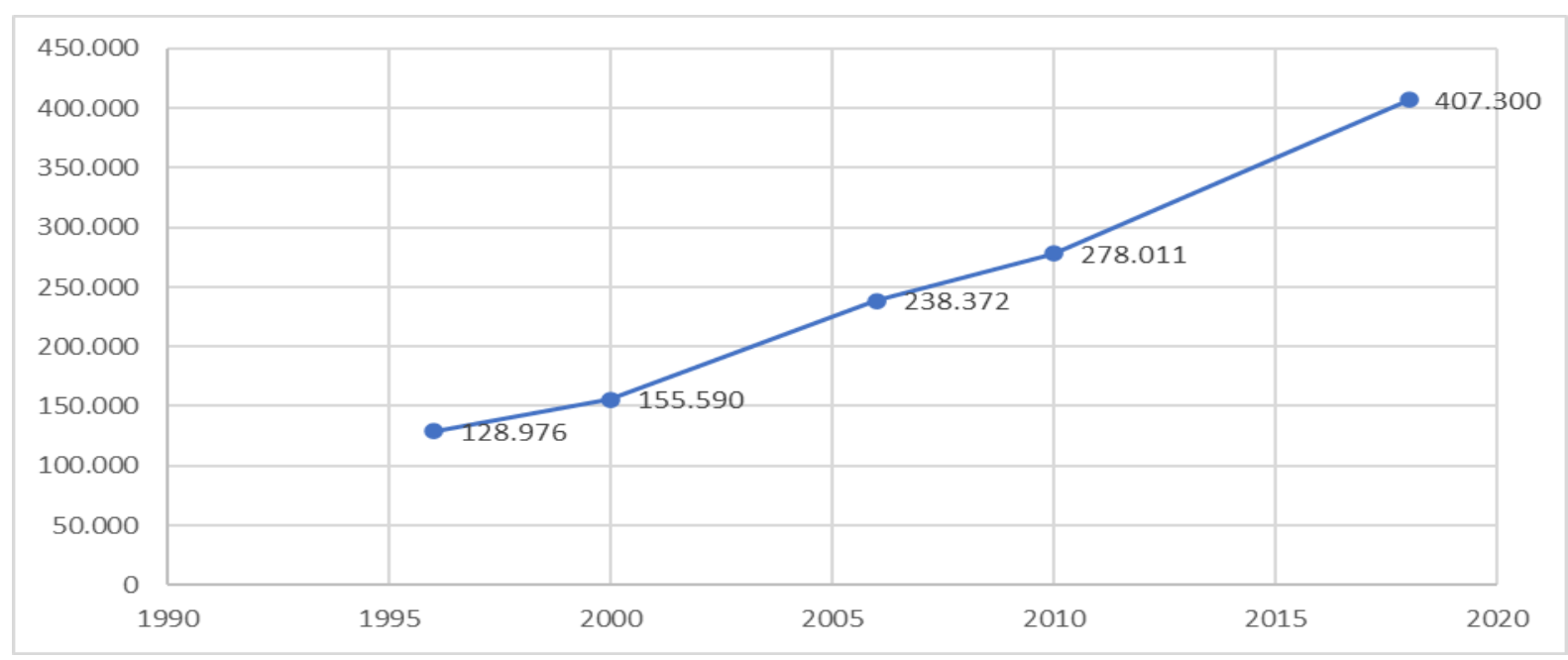

Fonte: Elaborado pelos autores a partir de ILOS (2002) e ANTT (2019)

De acordo com o gráfico 1, nesses pouco mais de 20 anos, após as concessões da malha ferroviária, o crescimento do transporte ferroviário de cargas sempre esteve em progresso constante, com crescimento de mais de 200\% no período de 1996 a 2018.

Segundo a ANTT (2019), com relação à produção do transporte ferroviário de cargas, no período de 2006 a 2018, foram transportados mais de 6 milhões de toneladas úteis (TU). $O$ gráfico 2 apresenta a produção do transporte ferroviário de cargas em (\%), divido por subgrupo de mercadoria.

Gráfico 2 - Produção do transporte ferroviário em \%, divido por subgrupo de cargas, no período de 2006 a 2018
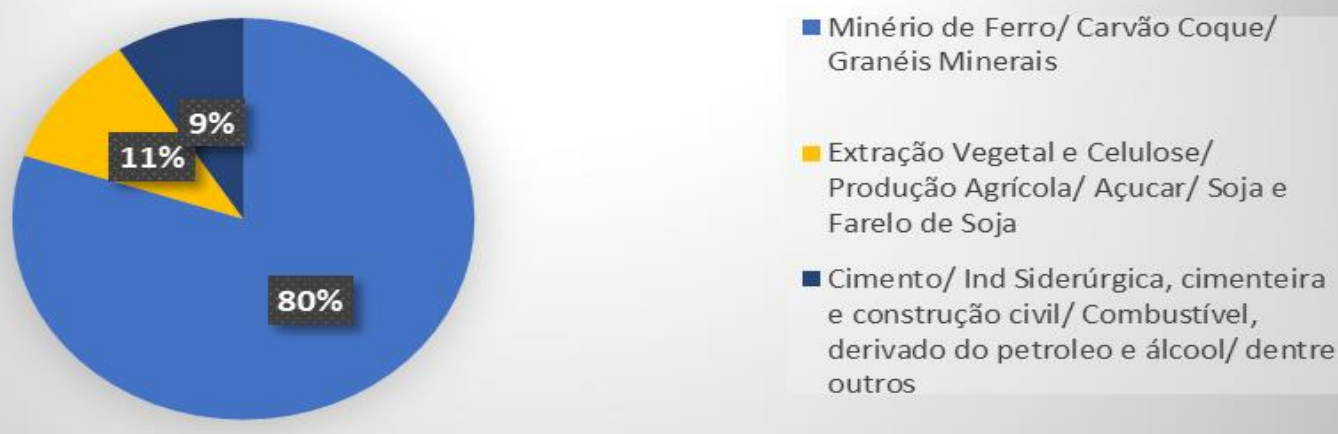
e construção civil/ Combustível, derivado do petroleo e álcool/dentre outros

Fonte: Elaborado pelos autores a partir de ANTT (2019)

Minério de Ferro, Carvão Coque e Granéis Minerais são as cargas que mais se destacam entre os produtos transportados pelo modal ferroviário. Todavia, apenas o minério de ferro, no ano de 2018, representou aproximadamente $77,5 \%$ do total das cargas transportadas em TU (ANTT, 2019).

Dessa forma, o gráfico 3, apresenta a evolução da produção do transporte ferroviário de cargas com relação ao minério de ferro, no mesmo período de 2006 a 2018. 
Gráfico 3 - Evolução da produção do transporte de minério de ferro em TU pelo modal ferroviário

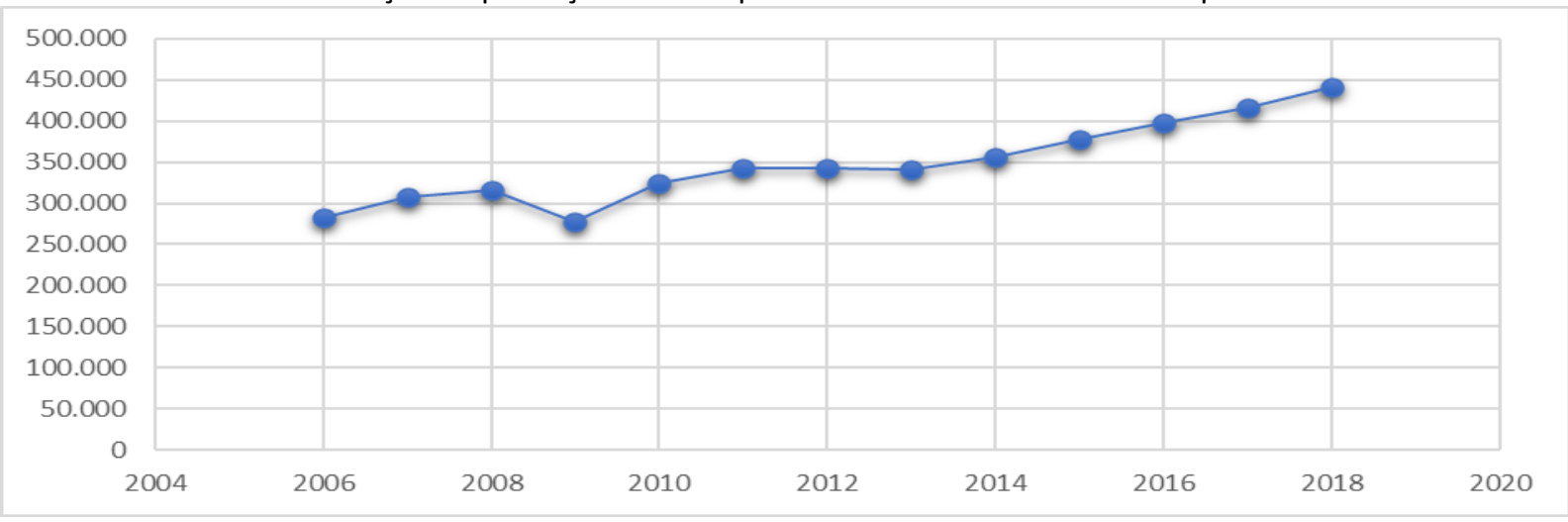

Fonte: Elaborado pelos autores a partir de ANTT (2019)

Vê-se claramente que ao longo dos anos a produção de transporte do minério de ferro foi aumentando constantemente e essa evolução também diz respeito a quase todos os outros tipos de cargas já citados.

Dessa forma, pode-se afirmar que ano após ano a capacidade de transporte de carga das ferrovias também aumentou, devido aos investimentos realizados no setor pela União e principalmente pela iniciativa privada.

\section{CONSIDERAÇÕES FINAIS}

O presente estudo buscou realizar uma análise dos impactos que as concessões na década de 1990 trouxeram para o setor ferroviário. Dessa forma, observou-se que houveram mais impactos positivos do que negativos para o setor.

Antes das concessões do setor ferroviário, os investimentos realizados pela União não eram suficientes para suprir as demandas e, após as concessões, a União passou a investir um pouco mais, ainda sendo pouco quando comparado com a iniciativa privada.

Pode-se afirmar que os investimentos realizados pelo setor privado chegam a ser mais que o dobro dos investimentos realizados pelo setor público. Esse dinheiro injetado pelas concessionárias contribuiu muito para a reestruturação do transporte ferroviário, auxiliando na retomada da construção de outras linhas como também na manutenção dos trilhos e vagões, fora a introdução de novas tecnologias de tráfego. Além dos avanços citados, houve uma significativa redução no número de acidentes, aumento de empregos diretos e indiretos, aumento da participação do modal ferroviário na matriz de transportes brasileira e, principalmente, aumento na produção de transporte ferroviário de cargas, com destaque para o minério de ferro, que é a carga com maior volume transportada pelo modal ferroviário.

Porém, mesmo com o aumento dos investimentos desde que o setor foi concedido à iniciativa privada, a dimensão da malha ferroviária não evoluiu muito, sendo que há poucos projetos em andamentos para a expansão da malha ferroviária brasileira. Expandir a malha ferroviária, mais os custos de se obter uma concessão, são investimento altíssimos. Dessa forma, vê-se claramente a necessidade de maiores investimentos por parte do governo federal no setor ferroviário para que a carga de investimentos não fique somente com a iniciativa privada e, consequentemente, não afete os preços que os usuários pagam, impactando os custos dos transportes e do preço dos produtos que chegam ao cliente final. 
Adicionalmente, sugere-se como tema para futuros estudos análises dos impactos da concessão do setor ferroviário da década de 1990 no transporte ferroviário de passageiros.

\section{REFERÊNCIAS}

ANTF. A Evolução do Transporte Ferroviário Brasileiro Nos Últimos 15 anos: Conquistas, Avanços e Desafios. 2012. Disponível em: <https://www.antf.org.br/wp-

content/uploads/2017/01/rodrigo_vilaca-antf-menor.pdf>. Acesso em: 07/09/2019.

ANTF. Informações Gerais. Disponível em: <https://www.antf.org.br/informacoes-gerais/>. Acesso em: 07/09/2019.

ANTT. Agência Nacional dos Transportes Terrestres. Contrato de concessão da Ferrovia Norte-Sul é assinado. Disponível em:

<http://www.antt.gov.br/salalmprensa/noticias/arquivos/2019/07/Contrato_de_concessao_da_F errovia_NorteSul_e_assinado.html>. Acesso em: 22 de agosto de 2019.

ANTT. Anuário Estatístico. Disponível em: <

http://www.antt.gov.br/ferrovias/arquivos/Anuario_Estatistico.html>. Acesso em 08/09/2019.

BRASIL. SENADO FEDERAL. Governo avalia retomada total da ferrovia transnordestina.

Disponível em:< https://www12.senado.leg.br/noticias/materias/2019/11/05/governo-avaliaretomada-total-da-ferrovia-transnordestina>. Acesso em: 23/04/2020

CNS. Transnordestina Logística S/A. Disponível em: <

http://www.tlsa.com.br/conteudo_pti.asp?idioma $=0 \&$ conta $=45 \&$ tipo $=59542 \& p r S v=1>$. Acesso em: 08/09/2018.

DNIT. Departamento Nacional de Infra-Estrutura de Transportes. Incentivos do Governo Imperial. 2019. Disponível em:http://www1.dnit.gov.br/ferrovias/historico.asp. Acesso em: 23 de agosto de 2019.

IBGE. Séries Históricas - PIB. 2019. Disponível em:

https://www.ibge.gov.br/estatisticas/economicas/contas-nacionais/9300-contas-nacionaistrimestrais. html?=\&t=series-

historicas\&utm_source=landing\&utm_medium=explica\&utm_campaign=pib\%23evolucaotaxa\#tevolucao-taxa. Acesso em: 10/09/2019.

ILOS. Os Avanços do Transporte Ferroviário de Carga no Brasil após as Privatizações: Uma Análise segundo a perspectiva de usuários, prestadores de serviço e governo. 2002. Disponível em: < https://www.ilos.com.br/web/os-avancos-do-transporte-ferroviario-de-carga-no-brasilapos-as-privatizacoes-uma-analise-segundo-a-perspectiva-de-usuarios-prestadores-de-servico-egoverno/>. Acesso em: 03 de setembro de 2019.

KNOWLES, R. D. Passenger rail privatization in Great Britain and its implications, especially for urban áreas. Journal of Transport Geography. Vol. 6, No. 2, pp. 117-133, 1998. 
LOHMANN, G., OLIVEIRA, M. V. O. Transporte Ferroviário de Passageiros Turísticos: O estado da arte. Turismo em Análise. v.19, n.1, maio, 2008.

JUNIOR, A. O. M., ABREU, G. R., JUNIOR, Z. A., JUNIOR, D. M. P., SHITSUKA, D. Moreira. Malha Ferroviária de 1890 a 2016: uma estrutura desfragmentada na história brasileira. Research, Society and Development, v. 7, n. 9, p. 01-18, e1379442, 2018.

LIMA, E. T., PASIN, J. A. B. Regulação no Brasil: colocando a competitividade nos trilhos. Revista do BNDES, v. 6, n. 12, p. 188, 1999.

MARCONI, M. A., LAKATOS, E. M., Metodologia do trabalho científico: procedimentos básicos, pesquisa bibliográfica, projeto e relatório, publicações e trabalhos científicos. 7. ed. São Paulo: Atlas: 2011.

MINISTÉRIO DA INFRAESTRUTURA. Investimentos. 2019. Disponível em :<http://www.transportes.gov.br/images/SITE_-_Investimento_e_Invers\%C3\%A3o__Fechado.pdf> Acesso: 04/09/2019.

MINISTÉRIO DA INFRAESTRURUA. Síntese do Setor Ferroviário. 2020. Disponível em:< https://www.infraestrutura.gov.br/component/content/article.html?id=5380> Acesso em 23/04/2020.

POCHMANN, M. Estado e Capitalismo no Brasil: a inflexão atual no padrão das políticas públicas no ciclo da nova república. Edu. Soc., Campinas, v. 38, n. 139, p. 309-330, jun. 2017.

RESENDE, P. T. V., OLIVEIRA, M. P. V., SOUZA, P. R. Análise do Modelo de Concessão no Transporte Ferroviário Brasileiro: a Visão dos Usuários. Revista do Mestrado em Administração e Desenvolvimento Empresarial da Universidade Estácio de Sá. ano 9, v.13, n.3, p.40-59, setembro/dezembro, Rio de Janeiro, 2009.

SANTOS, D. B., LIMA, R. C., BASSI, R. L., RODRIGUES, E. F., MAIELLARO, V. R. A. Infraestrutura do Transporte Ferroviário no Brasil. South American Development Society Journal. Vol. 04, №10 Ano 2018. 